\title{
Experimental Study on Adjustment of Inlet Nozzle Section to Flow Rate Variation for Darrieus-type Hydro-Turbine
}

\author{
Satoshi Watanabe ${ }^{1}$, Kai Shimokawa ${ }^{2}$, Akinori Furukawa ${ }^{1}$, \\ Kusuo Okuma ${ }^{1}$, and Daisuke Matsushita ${ }^{1}$
}

${ }^{1}$ Department of Mechanical Engineering, Kyushu University

744 Motooka, Nishi-ku, Fukuoka 819-0395, Japan, fmnabe@mech.kyushu-u.ac.jp, fmfuru@mech.kyushu-u.ac.jp, kokuma@mech.kyushu-u.ac.jp, matu@mech.kyushu-u.ac.jp

${ }^{2}$ Graduate School of Engineering, Kyushu University

744 Motooka, Nishi-ku, Fukuoka 819-0395, Japan, k.shimokawa@fcs.mech.kyushu-u.ac.jp

\begin{abstract}
A two dimensional Darrieus-type turbine has been proposed for the hydropower utilization of extra-low head less than $2 \mathrm{~m}$. In a practical use of Darrieus-type hydro-turbine, head and flow rate may be varied temporally and seasonally. Considering that the cost advantage is required for the low head hydro turbine system, the Darrieus turbine should be operated with high efficiency in the wider range of flow rate possibly by using an additional device with simpler mechanism. In the present paper, an adjustment of inlet nozzle section by lowering the inlet nozzle height is proposed to obtain the preferable inlet velocity in low flow rate conditions. Effects of resulting spanwise partial inlet flow are investigated. Finally, an effective modification of inlet nozzle height over flow rate variation is shown.
\end{abstract}

Keywords: Hydro-turbine, Darrieus-type runner, Inlet nozzle, Partial inlet flow, Self-starting characteristics

\section{Introduction}

The promotion of utilizing renewable energy resources is becoming an effective solution for environmental and energy problems. Hydropower is one of the major renewable energies. The high head hydropower generation plant, required to be installed with the large scale structure like a dam, however, is difficult to be newly constructed because the remaining unused site is limited considering the extensive impact for ecological system. On the other hand, the low head, especially extra-low head less than $2 \mathrm{~m}$, hydropower has not yet been developed. There are many sites of low head hydropower near the urban area. It is expected therefore as a local energy resource as the same as photovoltaic and wind power generations. A Darrieus-type hydro-turbine system for extra-low head hydropower has been proposed and developed by the present authors and their co-workers. Some characteristics on Darrieus-type runner, for instance the simple structure with two-dimensional blades and the high speed type runner permitting the runner to be operated in low inlet flow velocity conditions, are helpful for the extra-low head hydropower generation. Previous researches made clear the following facts:

(1) The most preferable runner geometry consists of two-dimensional NACA0018 blades equipped with the blade end plates avoiding blade tip effects and the streamlined support arms reducing a frictional torque loss.

(2) Five bladed runner is recommended because of good turbine performance and good self-starting characteristic.

(3) Provided the inlet nozzle is installed, the generated torque is improved. In addition, a drastic simplification, which includes the removals of draft tube and runner casing, is possible.

For the detail of optimum design, see Ref. [1]-[4].

In a practical use of Darrieus-type hydro-turbine, an operation with flow rate variation cannot be avoided if we utilize the existing natural open channels. When the flow rate decreases less than a designed one, a shortage of inlet flow velocity causes the severe deterioration of generated power and finally the turbine may falls into the shutdown. In addition, considering the rotation of Darrieus runner is sustained by the blade lift forces, the torque in stationary conditions is not enough for the turbine to be started from the stopping state. For the Darrieus-type hydro-turbine with a vertical axis, even if the flow rate in the channel is reduced to less than the designed one, the successive operation is required in terms of generation cost and ease of maintenance. In the present paper, a way of obtaining the sufficient inlet velocity for the continuous operation of Darrieus-type is proposed with the idea of lowering the inlet nozzle height. With the proposed inlet nozzle, only some spans of blades are put in oncoming flow stream, then the effects of which on the turbine performances are experimentally investigated. 


\section{Experimental Apparatus}

Figure 1 shows the schematic view of test waterway with vertical axis Darrieus-type hydro-turbine. The test waterway is divided into two parts, up- and downstream channels with width of $1200 \mathrm{~mm}$. Water in upstream channel enters the runner section through the inlet nozzle with the width of $S_{i n}=400 \mathrm{~mm}\left(S_{i n} / D=0.80\right)$ and the variable height of $B_{n}$, where $D$ is the diameter of the Darrieus runner pitch circle, $D=500 \mathrm{~mm}$. Then, water from the runner section is discharged to the downstream channel directly. It has been known that, with the nozzle installed at the inlet of Darrieus turbine, no draft tube is necessary, which is generally installed for the static head recovery from the dynamic head of discharge flow. The blade span length $B$ is $300 \mathrm{~mm}$, and $B_{n} / B=1$ is a basic operational condition, where the inlet nozzle height $B_{n}$ is set to be equal to the blade span length $B$. At the designed point of the present system with the flow rate $Q_{0}=200 \mathrm{l} / \mathrm{s}$ and the head difference $H_{t 0}=0.544 \mathrm{~m}$, the present Darrieus turbine generates $P_{0}=350 \mathrm{~W}$ as the output power of generator including mechanical and electric losses with the turbine efficiency of $\eta_{0}=0.33$ including. A movable upper wall of inlet nozzle can make narrow inlet section vertically and increases the inlet velocity under the constant flow rate of $Q$. The effective span length of blades for generating lift force corresponds to the changed nozzle height $B_{n}$. Five values of effective span ratios as $B_{n} / B=1.00,0.83,0.67,0.50$ and 0.33 are set in this experiment. In each nozzle height with $B_{n} / B$, the head difference $H_{t}$ between up- and downstream water levels, the generated power $P$, the flow rate and the rotational speed of runner shaft $N$ are measured after the head difference $H_{t}$ settled as steady flow. Here, the power $P$ is measured as the output one of generator, which depend only on the rotation of turbine axis system but not on flow velocity. The downstream water level $H_{d}$ is controlled by a movable weir put in the downstream channel as shown in Fig.1. The Darrieus runner is, in general, submerged for obtaining the preferable operating condition [3]. In the present Darrieus turbine system, the height from the bottom of the downstream channel to the upper supporting plate of the runner $L$ is $38 \mathrm{~cm}$. The coreless type electric-generator with 48 poles (Sky-denshi Co., SKY-HR350) is used under the same rotational speed of the generator and the runner. Experiments are performed with various electric loads to control the runner rotating speed under the constant flow rate condition. At first, the turbine performances in each $B_{n} / B$ are compared and the effects of spanwise partial inlet flow are discussed in the preferable conditions of downstream water level. Next, the relationship between the operative span ratio of $B_{n} / B$, the downstream water level $H_{d}$ and the turbine performances is investigated. Finally, the effects of changing the nozzle height on self-starting characteristics are shown.

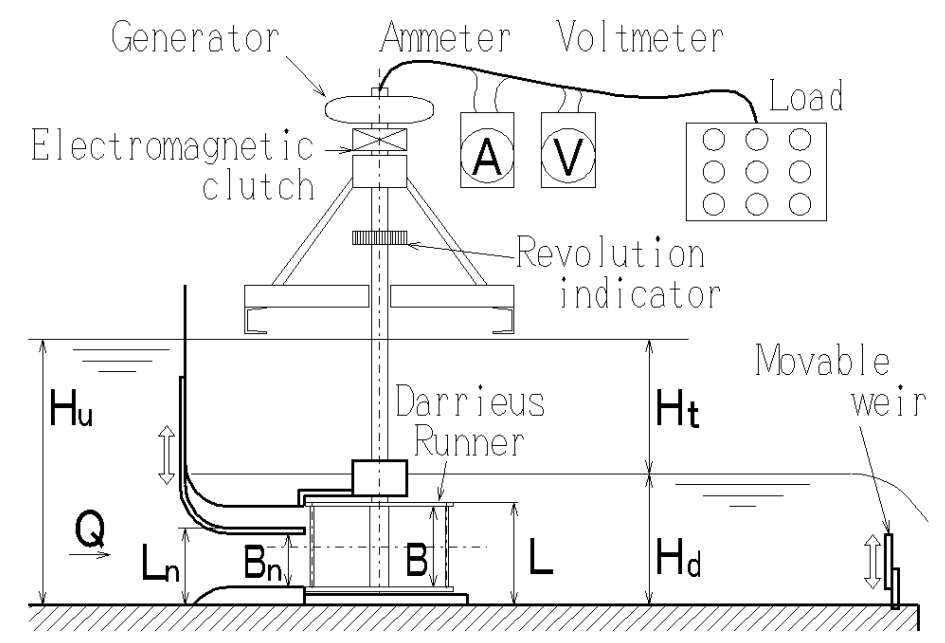

Fig. 1 Test apparatus of Darrieus turbine system and test water way

\section{Experimental results and discussion}

\subsection{Effects on turbine performances by change of operative span ratio}

Figure 2 depicts comparison of turbine performances with different operative span ratios $B_{n} / B$ under a constant inlet flow velocity of $V_{n}=1.25 \mathrm{~m} / \mathrm{s}$ (open symbols) as well as under a constant flow rate of $Q=100 \mathrm{l} / \mathrm{s}$ (closed symbols). The downstream water level is kept sufficiently high as $H_{d}=50 \mathrm{~cm}$ against the runner height $L=38 \mathrm{~cm}$. The horizontal axis of Fig. 2 means the speed ratio which is the ratio of the blade peripheral speed to the average velocity at the inlet nozzle section $U / V_{n}$ and each vertical axis means (a) the head coefficient $C_{h} / Z$, (b) the power coefficient $C_{p} / Z$ and (c) the turbine efficiency $\eta$, respectively, where $C_{h}=H_{t} /\left(V_{n}^{2} / 2 \mathrm{~g}\right), C_{p}=2 P /\left(\rho V_{n}^{3} B_{n} S_{i n}\right), \eta=P /\left(\rho \mathrm{g} Q H_{t}\right)=C_{p} / C_{h}, Z$ the number of blades, $\rho$ fluid density and $g$ the acceleration of gravity. The lack of data with $B_{n} / B=0.33$ under $Q=100 l / \mathrm{s}$ in $U / V_{n}>1.55$ is due to just limitations of the test waterway on permissible upstream water level. If the flow would be two-dimensional and the generated torque would be exerted in proportion to $B_{n} / B$, the performance curves of $C_{h}, C_{p}$ and $\eta$ would be supposed to take the same to those of $B_{n} / B=1.0$ from their definition, but this supposition is not observed in Fig. 2. Figure 2(b) shows the remarkable degradation of power coefficient with the decrease of $B_{n} / B$. The upper $\left(B-B_{n}\right)$ part of blade is rotating in the almost stagnant water, which does not generate the driving torque but the negative torque instead, resulting in the deterioration of power coefficient of turbine. The loss due to the negative torque becomes larger when the operative span length $B_{n}$ is shorter and the rotational speed of runner is faster. Consequently, the operational region in terms of the speed ratio shifts to the direction of low speed ratio with the decrease of $B_{n} / B$. The head coefficient, depicted 

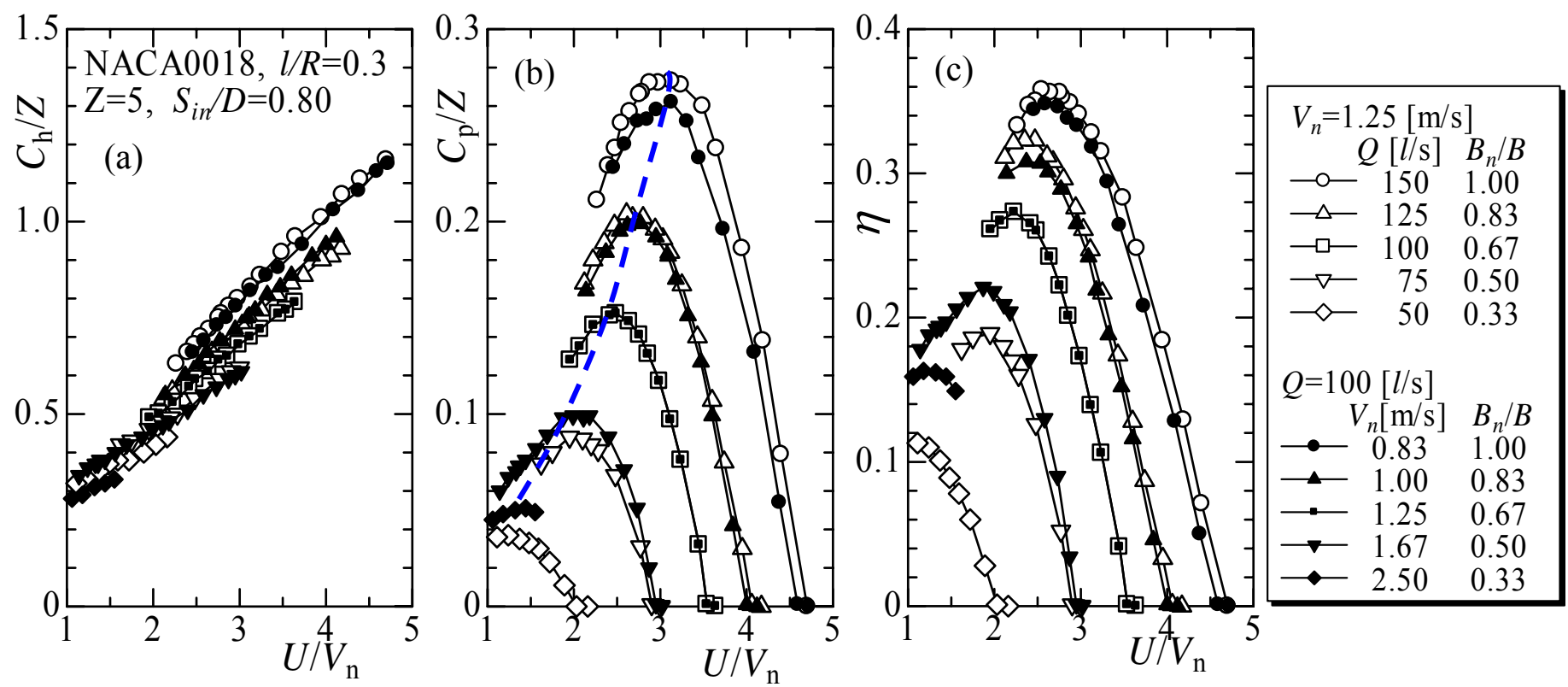

Fig. 2 Turbine performances with various $B_{n} / B$ under a constant velocity $\left(V_{n}=1.25 \mathrm{~m} / \mathrm{s}\right)$ and flow rate $(Q=100 \mathrm{l} / \mathrm{s})$

in Fig. 2(a), represents a total consumed head consisting of that at the runner and the passage head loss due to the sudden expansion from the nozzle to the downstream channel. The decrease of $C_{h} / Z$ due to the decrease of $B_{n} / B$ is smaller than that of $C_{p} / Z$, resulting in the decrease of turbine efficiency as shown in Fig. 2 as (a). In this case, the shaft power loss due to the negative torque of the upper $\left(B-B_{n}\right)$ part of blade is superior to the water power loss due to the passage head loss as described above. Both the performances under a constant inlet velocity and constant flow rate conditions are basically similar. Therefore, it is understood that the turbine performances with the change of inlet nozzle height can be evaluated through the operative span ratio $B_{n} / B$.

We have discussed on the variation of turbine performance with the decrease of $B_{n} / B$, focusing on the performance coefficients such as $C_{h} / Z, C_{p} / Z$ and $\eta=C_{p} / C_{h}$. In the practical operation in existing natural open channels, the operating point is determined by a real response of the generated power and the head difference between up- and downstream water levels against the flow rate variation. In the present study, aiming at improving the performance with the flow rate becoming less than the designed one, it is important to find the relation between the real generated power $P$ and the decreased flow rate $Q$. Figure 3 represents the reducing tendency on generated power $P$ with the decrease of $Q$ in the original nozzle geometry of $B_{n} / B=1.0$. The horizontal axis of Fig.3 means the rotational speed of runner $N$, and the vertical one the generated power $P$. Each power curve with the various flow rates is just estimated from the power coefficient with the designed flow rate of $Q_{0}(=200 \mathrm{l} / \mathrm{s})$. The maximum power under $Q=\mathrm{constant}$ is varied in accordance with $P_{b}=\left(Q / Q_{0}\right)^{3} P_{0}$ as shown by a dotted-dash line in Fig. 3, where $P_{0}$ is the maximum power (=350W) at $Q_{0}$. We can see the significant degradation of power with the decrease of the flow rate with keeping $B_{n} / B$ constant. Figure 4 shows

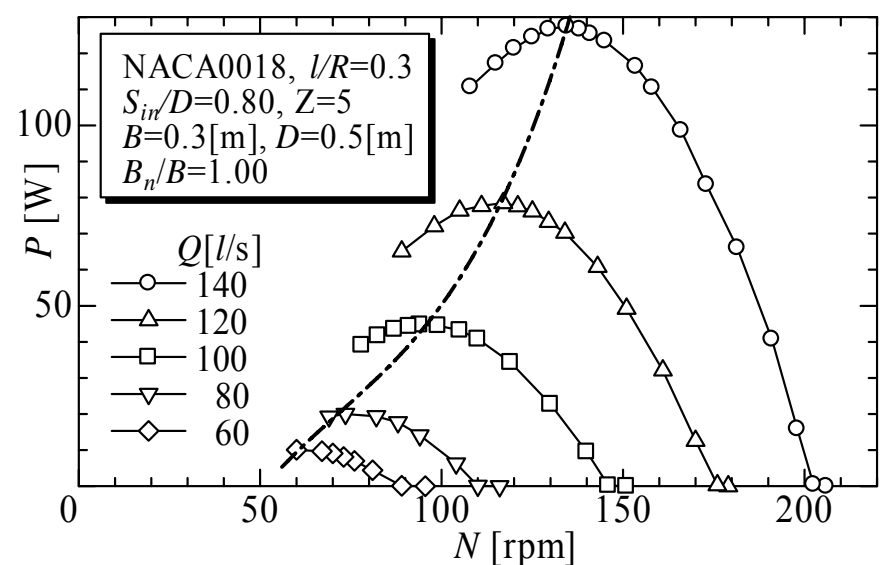

Fig. 3 Change of Generated power of Darrieus runner with $B_{n} / B=1.00$

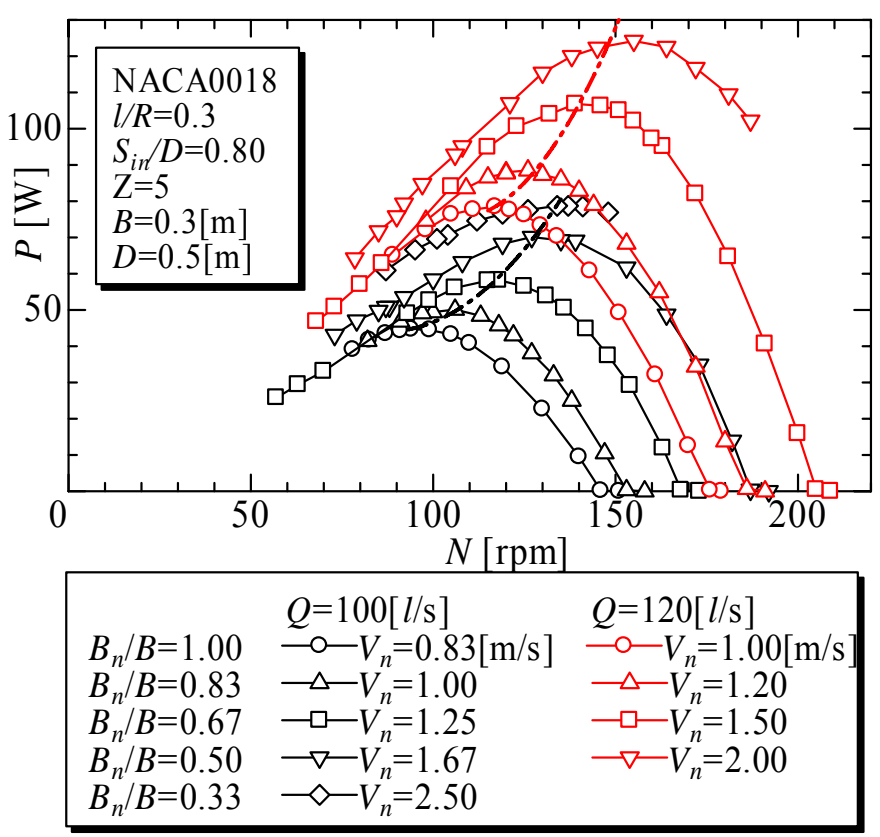

Fig. 4 Generated power with various $B_{n} / B$ under constant flow rate 


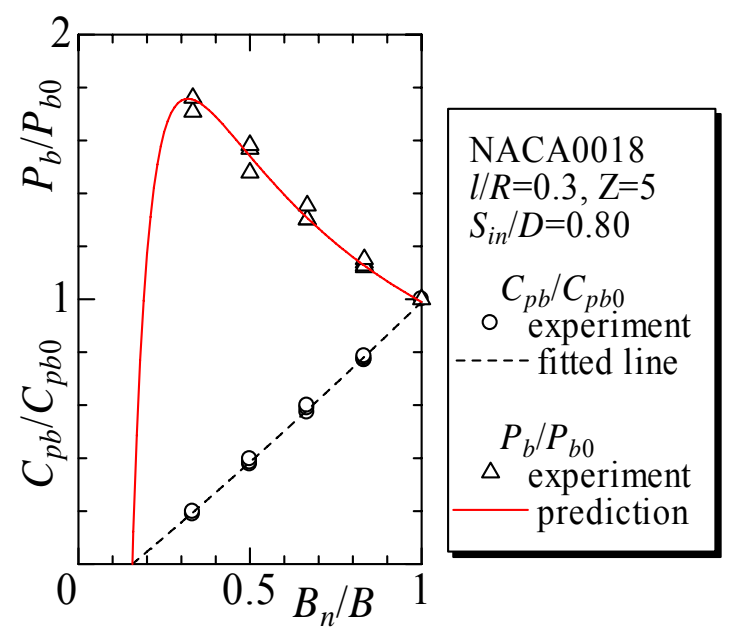

Fig. 5 Generated power prediction by decrease in operative blade span ratio $B_{n} / B$

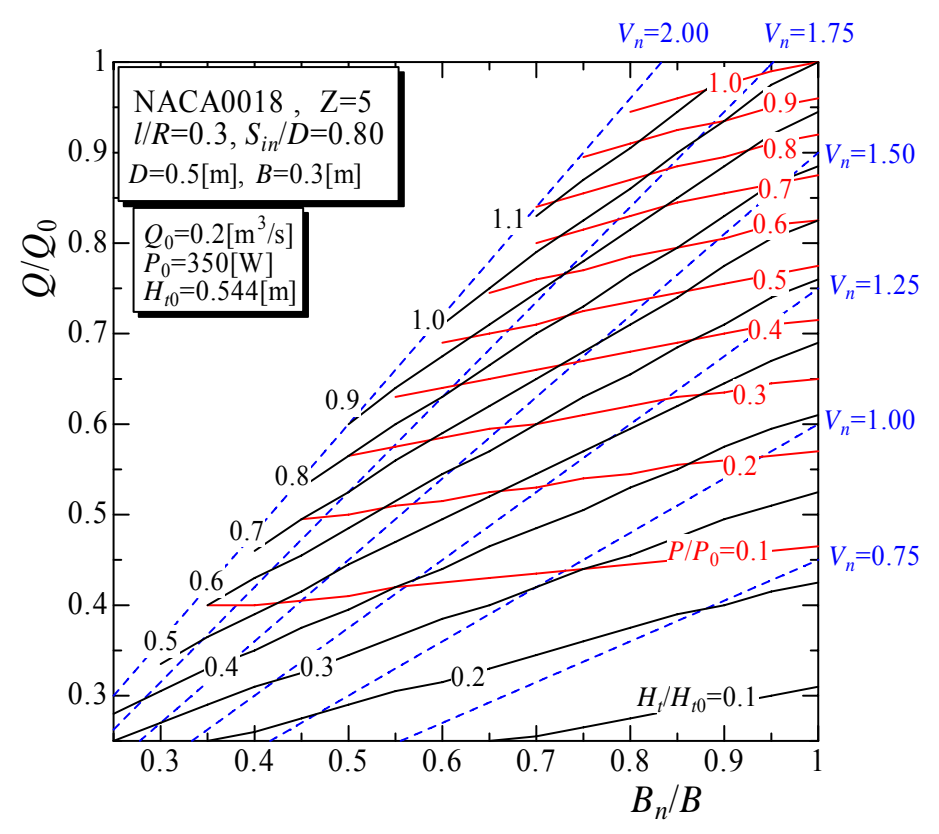

Fig. 6 Performance distribution on generated power ratio and head ratio by changes of flow rate and operative span

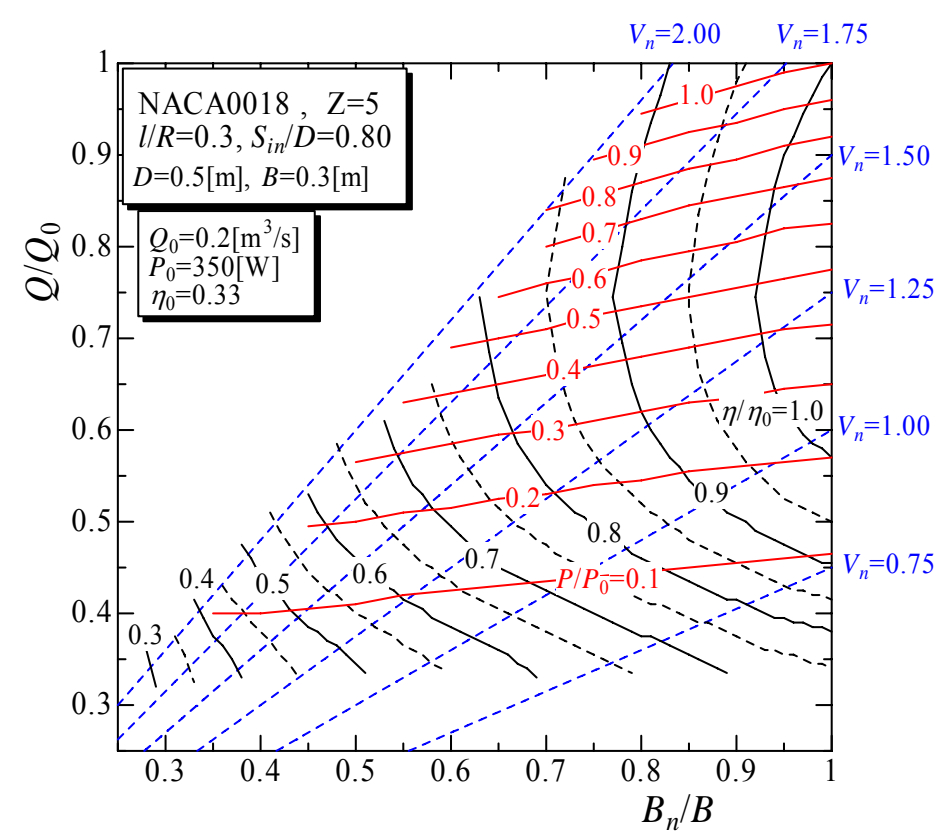

Fig. 7 Performance distribution on generated power ratio and efficiency ratio by changes of flow rate and operative span

the variations of $P-N$ curves with the change in $B_{n} / B$ for two lowered flow rates of $Q=100$ and $120 \mathrm{l} / \mathrm{s}$. We can find that, by decreasing the inlet nozzle height $B_{n}$, we can successively increase the generated power $P$, while the power coefficient $C_{p}$ decreases as has been seen in Fig. 2. By reducing $B_{n}$, we can increase the inlet flow velocity, which is much effective for the increase of the power as can be understood from $P=0.5 \rho Q V_{n}^{2} C_{p}$. We can notice the fact that the consumed head $H=C_{h} V_{n}^{2} /(2 \mathrm{~g})$ also increases with the increase of the inlet velocity $V_{n}$ by the decrease of $B_{n} / B$, which again explains the increase of the generated power by $P=(\rho \mathrm{g} Q H) \eta$. As a result, it is clarified that the adjustment of inlet nozzle height to increase the inlet velocity is an effective way for the lower flow rate turbine operation.

Next, in order to find the effective applicable flow rate range of inlet nozzle height adjustment, the maximum generated power obtainable by adjustment of the nozzle height $B_{n}$ is discussed. Figure 5 shows the variations of the maximum power ratio $P_{b} / P_{b 0}$ and the corresponding power coefficient ratio $C_{p b} / C_{p b 0}$ with the decrease of $B_{n} / B$ in three cases of $Q=80,100$ and $120 \mathrm{l} / \mathrm{s}$. $P_{b 0}$ and $C_{p b 0}$ are the maximum values with the original inlet nozzle height $\left(B_{n} / B=1.0\right)$. As mentioned in Fig. 2, the power coefficient decreases with decreasing $B_{n} / B$, and the turbine efficiency falls down. The result of $C_{p b} / C_{p b 0}$ shows a linear tendency, which is approximated by $C_{p b} / C_{p b 0}=\left\{\left(B_{n} / B\right)-k\right\} /(1-k)$, where $k=\left(B_{n} / B\right)_{C p b=0} \approx 0.16$, as indicated by the broken line in Fig. 5 . Since the real power ratio can be expressed by $P_{b} / P_{b 0}=\left(C_{p b} / C_{p b 0}\right) /\left(B_{n} / B\right)^{2}$, the maximum value of $P_{b} / P_{b 0}$ is found to be $\left(P_{b} / P_{b 0}\right)_{\max }=1 /\{4(1-$ $k) k\} \approx 1.86$ at $\left(B_{n} / B\right)_{P \max }=2\left(B_{n} / B\right)_{C p b=0} \approx 0.32(=2 k)$. Then, this fact implies that, although the maximum power coefficient deceases with the decrease of the inlet nozzle height, the output power can be increased in the low flow rate conditions. The maximum increase of the output power can be realized at $B_{n} / B=2 k$, where the value of $k$ is determined by net generated power, mechanical loss and generator loss which depend on each turbine system. The practical control range of inlet nozzle height should be $B_{n} / B>2 k=0.32$, in which the increment of $V_{n}$ is dominant over the variations of generated power. Meanwhile, the possibility of overflow in the upstream channel or the performance degradation by the occurrence of cavitation with increased inlet velocity may set a limit to operational range under $B_{n} / B<0.5$. 
For practical applications, a guide of selecting an inlet nozzle height in low flow rate conditions is shown in the case of the present hydro-turbine system as an example. Figures 6 and 7 depict the contour maps of head difference ratio $H_{t} / H_{t 0}($ black colored solid lines in Fig.6), generated power ratio $P / P_{b}$ (red colored solid lines in Figs.6 and 7) and efficiency ratio $\eta / \eta_{0}$ (black colored solid lines in Fig.7), where $P_{0}=350 \mathrm{~W} H_{t 0}=0.544$ and $\eta_{0}=0.33$ at the designed flow rate of $Q_{0}=200 l / s$. The horizontal and vertical axes of Figs. 6 and 7 are the operative span ratio $B_{n} / B$, and the flow rate ratio $Q / Q_{0}$ respectively. The broken lines in these figures express the ones with constant inlet velocity $V_{n}$. The permissible area for adjusting $B_{n} / B$ is supposed to $0 \leq Q / Q_{0} \leq 1$, $0.3 \leq B_{n} / B \leq 1, V_{n} \leq 2.0 \mathrm{~m} / \mathrm{s}$ in these figures [5]. The maximum inlet velocity set here is $V_{n}=2.0 \mathrm{~m} / \mathrm{s}$ for the margin to the occurrence of cavitation. Since the inlet velocity is set to $V_{n}=1.7 \mathrm{~m} / \mathrm{s}$ at the designed condition of $\left(B_{n} / B, Q / Q_{0}\right)=(1,1)$, the generated power is found to increase from the designed one due to the increased inlet velocity with the slight inlet nozzle height adjustment. However, taking account of avoiding the flooding in the upstream channel, the limit of $H_{t} / H_{t 0} \leq 1.0$ should not be violated. Besides, there is higher efficiency area against the design point, $\eta / \eta_{0}>1$, around $\left(B_{n} / B, Q / Q_{0}\right)=(1,0.8)$ in Fig. 7 . This is simply due to the generator characteristics. It is found from Fig. 6 that, although the decrease of $Q / Q_{0}$ under $B_{n} / B=$ constant causes the monotonous degradation of the maximum power $P / P_{0}$, it can be increased by the appropriate adjustments of operative span ratio $B_{n} / B$. However, in the lower flow rate conditions, the net generated power becomes remarkably small due to the corresponding low inlet velocity, and the adjustment of inlet nozzle height is not effective any more. Then, considering the practical application, the $50 \%$ flow rate of designed one may be effective as lower limitation. It is also confirmed from Fig. 6 that, under the constant flow rate, the increasing rate of $H_{t} / H_{t 0}$ with the decrease of $B_{n} / B$ is larger than that of $P / P_{0}$. This results in the decrease of efficiency $\eta / \eta_{0}$ as shown in Fig. 7. Note that, in such off-design conditions, the increase of generated power is often more important than the decrease of efficiency especially for small hydropower utilizations.

\subsection{Effects of change in operative span ratio and downstream water level}

The performance of vertical axis Darrieus-type hydro turbine is known to be significantly affected by downstream water level; the turbine performances decrease remarkably in a condition that the downstream water level becomes less than the upper supporting arm of the runner [3]. In the previous section, it has been clarified that the adjustment of inlet nozzle height $B_{n}$ is helpful for the operation at lower flow rates, while an ineffective part of blade [span of $\left(B-B_{n}\right)$ ] rotating in the stagnant water yields the additional loss. For this reason, the effects of downstream water level with the different operative spans $B_{n}$ on the turbine performances are investigated. The downstream water level $H_{d}$ and the height of the upper wall of the inlet nozzle $L_{n}(\leq L$, Fig. 1) from the bottom of downstream channel are varied against the height of the upper supporting arm of the runner $L$ from the bottom of downstream channel, which is $38 \mathrm{~cm}$ in the present turbine system.

First of all, the effects of variations of downstream water level $H_{d}$ on the turbine performances under $B_{n} / B=1.0\left(L=L_{n}\right)$ are shown in Fig. 8 [3]. Red colored lines represent the performances with sufficiently high water level $\left(H_{d}=52 \mathrm{~cm}=L+14 \mathrm{~cm}\right)$. Decreasing the downstream water level $H_{d}$, the power coefficient in the higher speed ratio $\left(U / V_{n}\right)$ range begins to decrease at $H_{d}$ $=42 \mathrm{~cm}$, then it decreases in the whole range of speed ratio within $H_{d}=40-38 \mathrm{~cm}$. Under these conditions, the interaction between the upper arm of the runner and the water surface causes the wavy motion of water surface, which results in the increment of loss of generated torque. When the water level $H_{d}$ becomes $35 \mathrm{~cm}$, which is lower than the runner height $L$, the operation can be done only in the high speed ratio range. In the lower speed ratio range including the expected maximum efficiency point, it is confirmed by the naked eye observation that air suction vortex appears on the suction surface of Darrieus blade. This can be a cause of sudden deterioration of generated torque in the low speed ratio range. From this reason, it has been recommended to keep the downstream water level sufficiently high against the runner height.

Next, Figure 9 shows the effects of variations of downstream water level on the turbine performances with the operative span ratio of $B_{n} / B=0.67$. As mentioned in Fig.2, the performance coefficients with decreased operative span ratio are, on the whole, inferior to those with $B_{n} / B=1.0$. With $B_{n} / B=0.67$, the height of the upper wall of the nozzle $L_{n}(=28 \mathrm{~cm})$ from the bottom of the
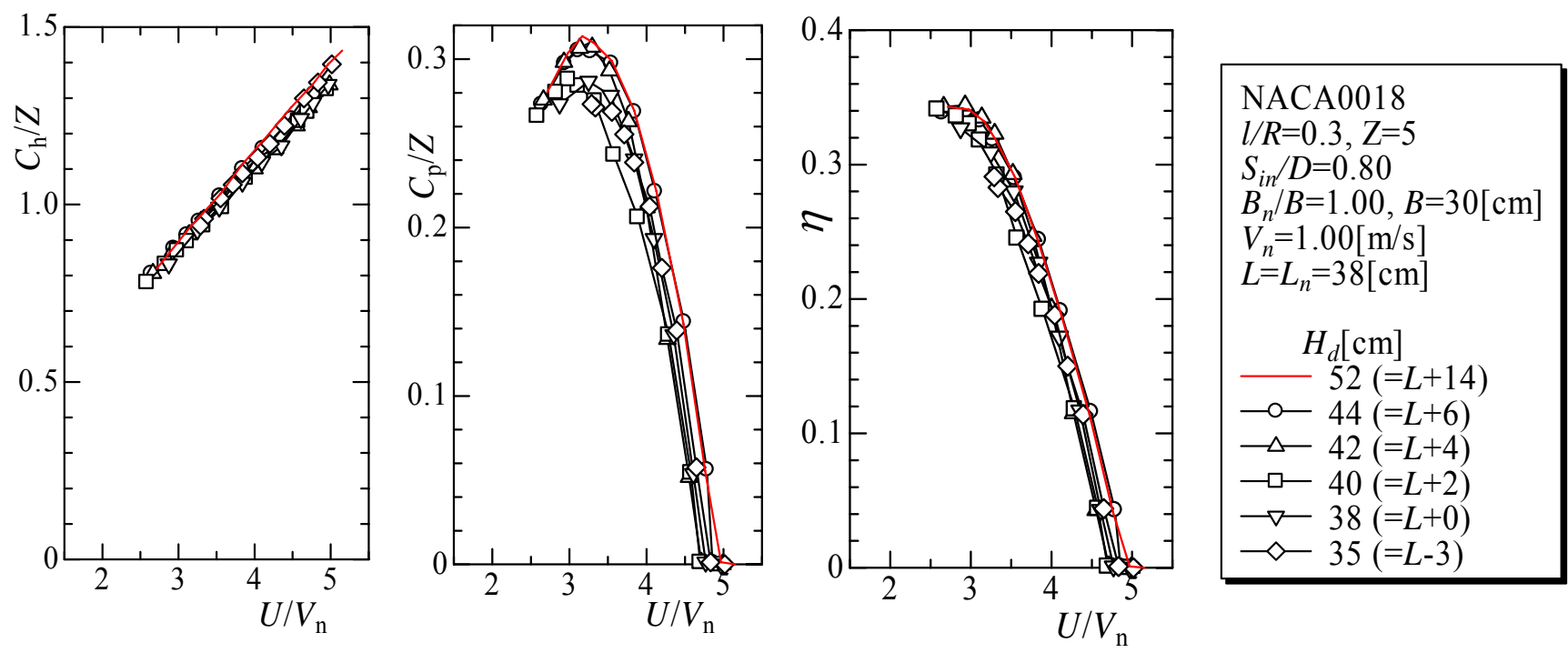

Fig. 8 Effect of the downstream water level on turbine performances in the standard nozzle geometry $\left(L_{n}=38 \mathrm{~cm}\right)$ 

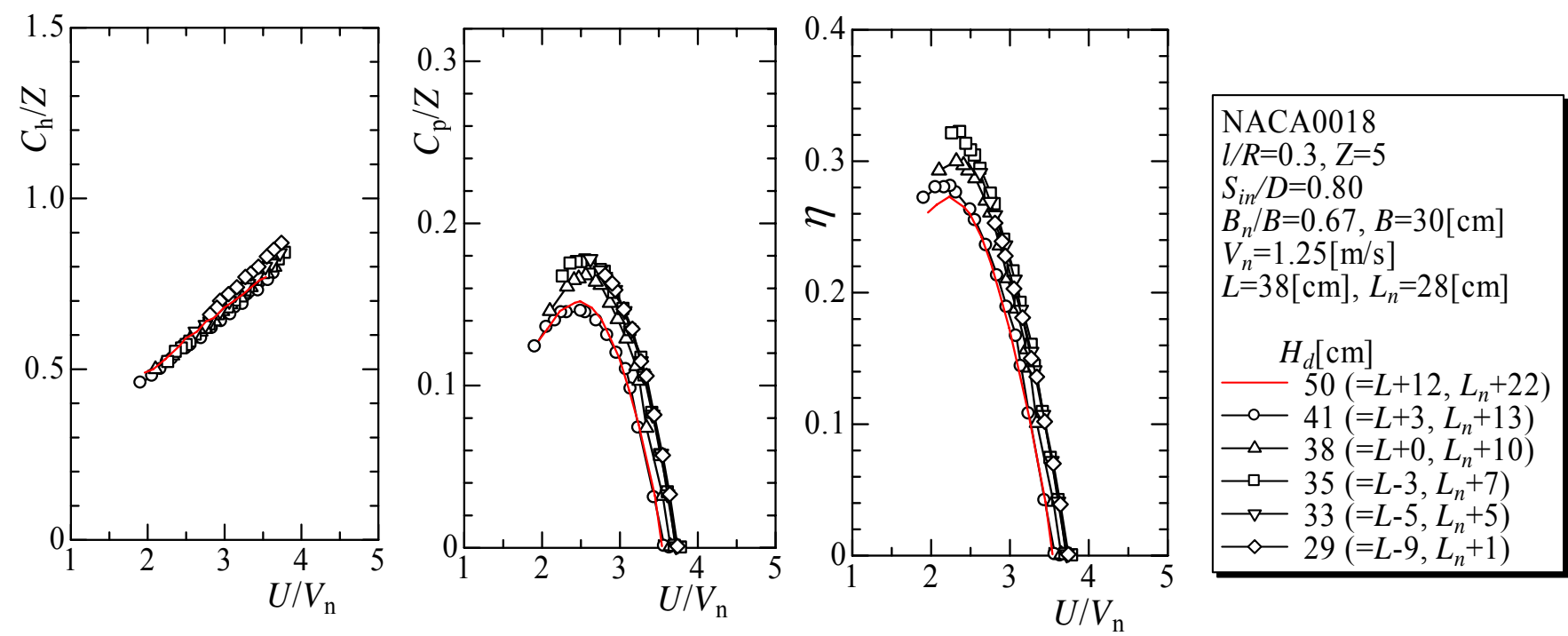

Fig. 9 Effect of the downstream water level on turbine performances in the varied nozzle geometry $\left(L_{n}=28 \mathrm{~cm}\right)$

downstream channel differs from the runner height $L(=38 \mathrm{~cm})$. Red colored lines depict the performances of the enough water Level $\left(H_{d}=50 \mathrm{~cm}=L+12 \mathrm{~cm}=L_{n}+22 \mathrm{~cm}\right)$. Even with the downstream water level of $H_{d}=41 \mathrm{~cm}$, where the water surface is close to the rotating upper arms of the runner, the degradation of power coefficients does not appear, which is different from the case with $B_{n} / B=1.0$ where the performance degradation occurs in the high speed ratio range as shown in Fig. 8. Moreover, further decrease of the downstream water level with $L_{n}<H_{d}<L$, for instance $H_{d}=38 \mathrm{~cm}$ and $35 \mathrm{~cm}$, remarkably increases the power coefficient and the turbine efficiency as can be noticed in Fig. 9. Finally, when the water level $H_{d}$ becomes lower than $33 \mathrm{~cm}$, the operation range becomes limited to the higher speed ratio range, which is similar to the case with $H_{d}=35 \mathrm{~cm}$ for $B_{n} / B=1.0$. In this case with $B_{n} / B=0.67$, the upper end plate appears above the downstream water surface and the upper nozzle wall is close to the water surface $\left(H_{d}-L_{n}=5 \mathrm{~cm}\right.$ below the surface), resulting in the occurrence of air suction vortex on the blade suction surface again in the low speed ratio range, namely the high blade loading conditions, and then the operation breakdown in this range. However, the power coefficients in the high speed ratio range still remain improved against those of normal condition of $H_{d}=50 \mathrm{~cm}$. When the water level $H_{d}$ becomes lower than the runner height $L$, the operative parts of blades with the span of $B_{n}$ work normally. The some part of ineffective spans $\left(B-B_{n}\right)$ of blades and the upper arms of the runner are rotating in the air and not in the stagnant water any more. Therefore, the rotating torque loss sharply decreases, resulting in the superior power coefficients with $H_{d} \leq L$ than those with $H_{d}>L$.

The results obtained from this experiment suggest a novel way of treatment of the downstream water level in the turbine operation. For the design of Darrieus hydro-turbine system, basically, a weir must be installed to obtain the sufficient water level against the runner height in the downstream water channel (refer to Fig. 1). The adjustment of inlet nozzle height can be applied to keep high generated power in the lower flow rate operation. However, the increase of head difference enhances the risk of flooding of upstream channel flow. If we can control the height of weir in addition to the inlet nozzle height adjustment, the risk of flooding can be reduced by lowering the downstream water level with adjusting the height of weir as well. In such cases, the power coefficient and the efficiency are also improved as discussed in Fig. 9. This suggests that, with simultaneous control of heights of inlet nozzle and downstream weir, it becomes possible to operate the turbine system successively with higher efficiency against the flow rate variation with the reduced risk of flooding.

\subsection{Effects of change in operative span ratio on self-starting characteristics}

The previous discussion has revealed the effectiveness of operative blade span adjustment on the successive operation at low flow rates. However, the limitation of the lowest flow rate is also discussed, which means that the incidental excessive decrease of flow rate might lead to the operation breakdowns. To recover from such conditions, a smooth self-starting characteristics, namely higher starting torque, is necessary at the flow rate as low as possible. However, since the Darrieus-type runner is one of the lift type, the generated torque in the stationary condition $(N=0 \mathrm{rpm})$ is generally small. In order to examine the possibility of enhancement of self-starting characteristics with the inlet nozzle adjustment, the torque measurement in the stationary condition is carried out by installing a torque meter instead of generator in the same experimental setup. Since the Darrieus runner is a crossflow type, the generated torque depends on the blade positions $\theta$ on the runner pitch circle. Therefore, the self-starting generated torque $T_{g}$ under a constant flow rate is measured at various blade peripheral positions $\theta$. The blade position with $\theta=\pi / 2$ corresponds to that at the most upstream.

Figure 10 shows the variations of torque coefficient with the various operative span ratios of $B_{n} / B$. The horizontal axis of Fig. 10 is the blade position $\theta$ and the vertical axis the torque coefficient defined as $C_{t}=T_{g} /\left(\rho V_{n}^{2} S_{i n} B_{n} R\right)$. As the test runner has 5 blades, the results only for $\theta=0-72$ degrees are plotted. It is found from the figure that the torque coefficient takes the minimum value at $\theta$ $=35$ degrees for all the examined operative span ratios of $B_{n} / B$. This means that the ineffective parts of blades $\left(B-B_{n}\right)$ do not generate torque since the flows are stationary around these parts. Consequently, it is clarified that the self-starting torque is simply decided by the torque of the operative parts of blade $\left(\operatorname{span} B_{n}\right)$ located in the oncoming flow with the velocity of $V_{n}$. 


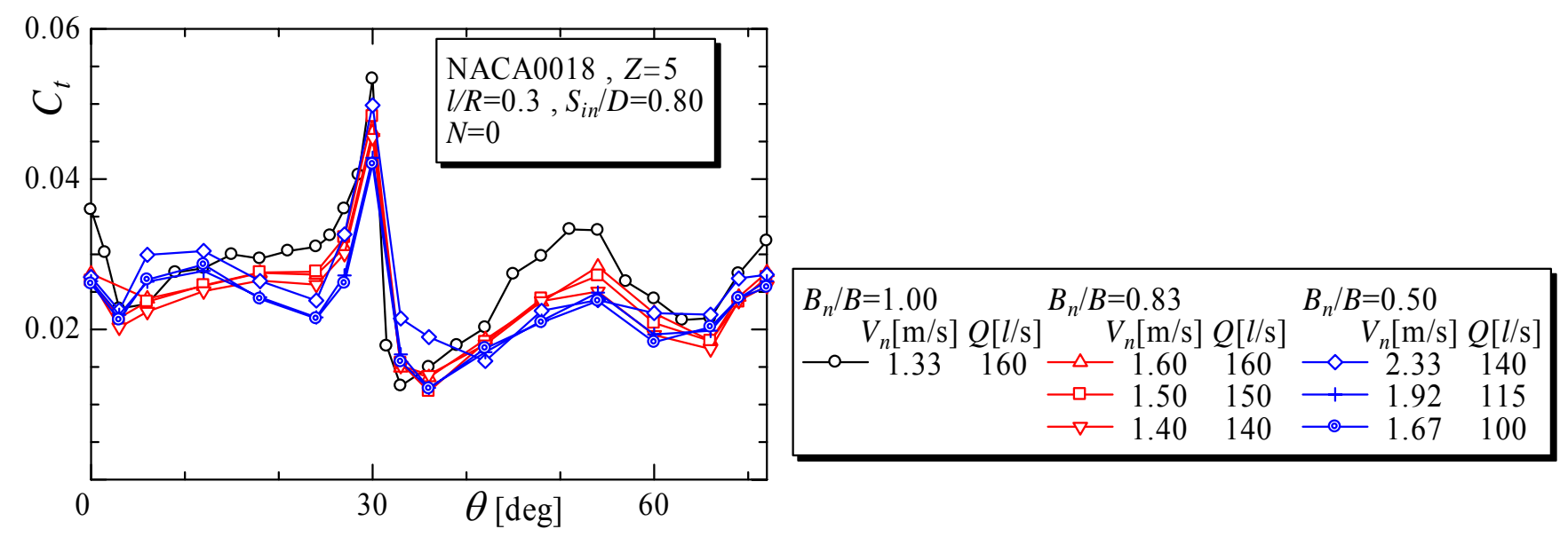

Fig. 10 Self-starting torque of 5 bladed Darrieus runner

As shown in Fig. 10, the starting torque coefficient $C_{t}$ is almost unchanged with the change of the operative span ratio of $B_{n} / B$. This is totally different from the fact that the power coefficient $C_{p}$ decreases with the decrease of $\left(B_{n} / B\right)$ due to the additional torque loss of the ineffective parts of blades rotating in the stagnant water. This implies that the adjustment of the inlet nozzle height is more effective for the increase of the self-starting torque. If a turbine with the nozzle height of $B_{n} / B=1.0$ obtains a torque $T_{g b}$ in a flow rate $Q$, the torque $T_{g}$ with varied nozzle height of $B_{n} / B(<1)$ for the same flow rate can be estimated using the relationship expressed by $T_{g}=T_{g b} /\left(B_{n} / B\right)$. Then, it is apparently clear that the self-starting characteristics of runner can be remarkably improved by the adjustment of inlet nozzle height.

\section{Conclusion}

Considering the flow rate shortage for the vertical-axis Darrieus-type hydro-turbine, for example, due to seasonal flow rate changes in natural flow passages, the active adjustment of inlet nozzle height is proposed to secure the sufficient turbine performances even in such severe conditions. The effects of spanwise partial inlet flow due to the adjustment of inlet nozzle height on turbine performances are experimentally investigated. Main conclusions are summarized as follows.

(1) The power coefficient and the turbine efficiency are deteriorated with the decrease of operative blade span length by making the inlet nozzle height being lower than the blade span.

(2) Appropriate decrement of operative blade span length increases the head difference, namely the potential energy, for the same flow rate. Then, the increment of real generated power can be achieved.

(3) The relationship between the upper end of the operative blade span and the downstream water surface affects the turbine performances. Provided that the ineffective parts of blades rotate above the water surface, the turbine efficiency improves because of the reduction of torque loss of the ineffective parts of blades.

(4) Self-starting torque can be evaluated simply by the torque coefficient defined using the operative span instead of the full blade span. Adjustment of inlet nozzle height greatly contributes to the improvement of self-starting characteristics.

\section{Nomenclature}

$B$

$B_{n}$

$C_{h}$

$C_{p}$

$C_{t}$

$D$

$\mathrm{g}$
$H_{t}$

$H_{t 0}$

l

$L, L_{n}$

$N$

$P$
Blade span length=inlet nozzle height [m]

Operative blade span length

=movable nozzle height $[\mathrm{m}]$

Head coefficient $\left(=H_{t} /\left(V_{n}^{2} / 2 \mathrm{~g}\right)\right)$

Power coefficient $\left(=2 \mathrm{P} / \rho V_{n}^{3} B_{n} S_{i n}\right)$

Torque coefficient $\left(=T_{g} / \rho V_{n}^{2} B_{n} S_{i n} R\right)$

Diameter of runner pitch circle [m]

acceleration of gravity $\left[\mathrm{m} / \mathrm{s}^{2}\right]$

Total head difference [m]

Total head difference at design point [m]

Blade chord length [m]

Runner and nozzle height

from the bottom of downstream channel [m]

Rotational speed of runner [rpm]

Power of generator [W]
Maximum power of generator [W]

at design point [W]

Flow rate $\left[\mathrm{m}^{3} / \mathrm{s}\right]$

Flow rate at design point $\left[\mathrm{m}^{3} / \mathrm{s}\right]$

Radius of runner pitch circle [m]

Width of inlet nozzle section [m]

Torque of runner [Nm]

Peripheral velocity of blade $[\mathrm{m} / \mathrm{s}]$

Velocity in inlet nozzle section $[\mathrm{m} / \mathrm{s}]$

Number of blades

Blade rotating position [deg.]

Fluid density

Turbine efficiency $\left(=P /\left(\rho \mathrm{g} Q H_{t}\right)=C_{p} / C_{h}\right)$

Corresponding turbine efficiency

at design point $Q$ and $P_{0}$ 


\section{References}

[1] Furukawa A., Watanabe S., Matsushita D. and Okuma K., 2010, "Development of Ducted Darrieus Turbine for Low-Head Hydropower Utilization," Current Applied Physics, Vol. 10, Supplement 2, pp. S128-S132.

[2] Matsushita D., Okuma K., Watanabe S. and Furukawa A., 2008, "Simplified Structure of Ducted Darrieus-type Hydro Turbine with Narrow Intake for Extra-low Head Hydropower Utilization,” J. of Fluids Science and Technology, Vol. 3, No 3, pp. 387-397.

[3] Shimokawa K., Furukawa A., Okuma K., Matsushita D. and Watanabe S., 2010, "Experimental Study on Simplification of Darrieus-type Hydro Turbine with Inlet Nozzle for Extra-low Head Hydropower Utilization," Proceedings of the Int'l Symposium on Low Carbon \& Renewable Energy Technology, Jeju, Korea, pp. 163.

[4] Furukawa A., Takenouchi K., Okuma K. and Watanabe S., "Utilization of Two-Dimensional Ducted Darrieus Turbine for Extra-low Head Hydropower," Proceedings of Expo World Conf. on Wind Energy, Renewable Energy, Fuel Cell \& Exhibition 2005, Hamamatsu, Japan, 4010, pp. 1-4.

[5] Takamatsu Y., Furukawa A., Okuma K., Takenouchi K., Sasaki T. and Cho K., 1992, "Studies on Cavitation Occurring on the Runner Blade of a Darrieus-Type Cross-Flow Water Turbine,” Japan Soc. Mech. Engrs. Inter. J., Ser. II, Vol. 35, No. 1 pp. 46-52. 